\title{
Kindness as an Intervention for Student Social Interaction Anxiety, Affect, and Mood: The KISS of Kindness Study
}

\author{
Katie J. Shillington ${ }^{1}$ (D) Andrew M. Johnson ${ }^{1,2}$ (D) Tara Mantler $^{1,2}$ (D) \\ Jennifer D. Irwin ${ }^{1,2}$
}

Accepted: 1 May 2020 / Published online: 14 May 2020

(C) Springer Nature Switzerland AG 2020

\begin{abstract}
This study assessed the incremental impact of performing acts of kindness, beyond the benefits seen from providing a resource booklet on stress management (that is available to all students at the host institution) with regard to the affect, social interaction anxiety, and mood of undergraduate students. This repeated-measures mixed methods study involved 69 full-time undergraduate students allocated to the intervention (kindness + stress booklet; $n=35$ ) or comparator (stress booklet; $n=34$ ) condition. The Brief Mood Introspection Scale, the International-Positive and Negative Affect Schedule-Short Form, and the Social Interaction Anxiety Scale-Straightforward were administered at pre- and immediate post-intervention. Inductive content analysis was performed on open-ended questions exploring participants' experiences with the study. No statistically significant results were found. Several themes highlighted self-perceived improvements in the wellbeing of intervention group participants. This study was perceived as a positive experience by many participants and demonstrated promise for a larger-scale university-based intervention.
\end{abstract}

Keywords Kindness · Social interaction anxiety · Mood · Affect · Undergraduate students

In recent years, the mental health of post-secondary students has been increasingly recognized as critical to understand (Auerbach et al. 2016; Blanco et al. 2008; Bruffaerts et al. 2018). This may, in part, be due to the many mental health issues that develop during young adulthood (Gibbons et al. 2018). In fact, some researchers

Jennifer D. Irwin

jenirwin@uwo.ca

1 Health and Rehabilitation Sciences, Faculty of Health Sciences, The University of Western Ontario, London, Ontario, Canada

2 School of Health Studies, Faculty of Health Sciences, The University of Western Ontario, HSB Room 338, 1151 Richmond Street, London, Ontario N6A 5B9, Canada 
recently found that self-reported mental health issues among university students have increased in both rate and severity (Gibbons et al. 2018; Kirsh et al. 2016). Gibbons et al. (2018) surveyed undergraduate students at a private university and found over half of the participants had experienced a mental health problem, at some point in their life, that persisted over two weeks; $35.4 \%$ said this experience occurred during college. The two most concerning mental health problems reported were stress and anxiety (58.3\% and $37.0 \%$, respectively; Gibbons et al. 2018).

Canadians' 'negative stress' (hereafter referred to as 'stress') levels increased between 2015 to 2017, with university students experiencing abnormally high levels compared to their community counterparts (Leahy et al. 2010; Stallman 2010; Statistics Canada 2019). In 2018, approximately $20 \%$ of males and 25\% of females aged 18 to 34 (an age range that includes many undergraduate students) indicated that most days were "quite a bit or extremely stressful" (Statistics Canada 2010, 2019, para 1). Stress can be understood as an individual's response to external pressures (Cook 2014; Selye 1956). A recent study revealed that the prevalence of elevated stress was significantly higher among Ontario undergraduate students than their non-student counterparts $(41.1 \%$ versus 15.5\%, respectively; Adlaf et al. 2001). Stoliker and Lafreniere (2015) found that stress among university students was associated with increased levels of burnout, which is characterized by physical and emotional symptoms such as gastrointestinal disorders and signs of depression (Heinemann and Heinemann 2017). High levels of stress have been associated with the suppression of the immune system leading to increased illness, such as the common cold, and in more severe cases, risk of developing cardiovascular diseases and hypertension, and premature death (Carroll et al. 2012; Chida and Steptoe 2010; Passer et al. 2008). Such high levels of stress among students might be associated with the inadequate resources (e.g., counselling services or social support) available for them to manage their stress (Barker et al. 2018). That is, according to Barker et al. (2018), elevation of perceived stress and associated negative affect, may, in part, be due to the relationship between threat and resource accessibility; an increase in stressors paired with a resource deficit can lead to risk of experiencing negative outcomes. If students perceive there are sufficient available resources to manage their stress levels, they might feel more equipped to cope versus if they perceive their resources to be inadequate, which might lead them to experience the negative outcomes of stress (Pratt et al. 2004). University students experience unique stressors such as pressure to succeed in academic settings, high parental expectations, worry surrounding future aspirations, and social integration, all of which can have a negative impact on their mental health - specifically in relation to stress and anxiety (Sreeramareddy et al. 2007).

Anxiety can be defined as an emotional state characterized by fear and/or tension that is provoked in situations where a potential threat is detected (Baumeister and Vohs 2007; Graeff 2007; Rector et al. 2008; Wongtongkam 2019). The most recent National College Health Assessment Surveys, which included responses from students attending Canadian postsecondary institutions, showed an increase in student anxiety from 2013 to 2016 (54.5\% versus 65.4\%, respectively; American College Health Association 2013, 2016). Additionally, according to the Association for University and College Counseling Center Directors, anxiety was the highest-ranking concern among college students in 2016, with an annual prevalence of $48.2 \%$ (LeViness et al. 2016). This is particularly problematic as Huang et al. (2018) found untreated student anxiety can 
result in lower self-esteem, social isolation, difficulty performing academically, and, in grave cases, suicide. Social anxiety, a specific form of anxiety, is particularly prevalent among college/university students with reported rates of 19 to 33\% (Beidel et al. 1989; Strahan and Conger 1998; Strahan 2003). Social anxiety can be characterized by fear or avoidance of social situations where the individual believes they are at risk of embarrassment, humiliation, or rejection, and it is associated with alcohol abuse, lower academic achievement, poorer health, and difficulty forming relationships (American Psychiatric Association 2017; Brook and Willoughby 2015; Ghaedi et al. 2010; Parade et al. 2010; Schry and White 2013). Of these negative consequences, particular consideration should be given to the challenges students face forming relationships due to social anxiety, as Kirsh et al. (2016) emphasized the importance of fostering relationships to protect against mental health concerns in university.

The relationship between social support and the mental health of university students can, in part, be explained by positive and negative affect. The American Psychological Association describes positive affect as including pleasant or satisfied feelings (American Psychological Association n.d.-a) and negative affect as dissatisfied or threatening feelings (American Psychological Association n.d.-b). Each internal state includes a range of possible arousal levels (e.g., positive affect can include feelings of heightened enthusiasm or calmness and negative affect can include high levels of heightened distress or sadness; Larsen et al. 2001; Watson et al. 1988; Watson et al. 1999). A number of researchers (e.g., Larsen et al. 2001; Rafaeli et al. 2007) contend that positive and negative affect (including different arousal levels) can co-exist concurrently, whereas others view them as inversely related, such that positive affect is associated with increased social support and decreased stress and negative affect is associated with the opposite experiences (Brannan et al. 2013; Green et al. 2012; Hamama et al. 2013; Jou and Fukada 2002; Nima et al. 2013). Positive affect has been linked to decreased depressive symptoms and related stress, as well as increased positive health behaviors (Griffin et al. 1993; Nima et al. 2013). Though studies have reported on the relationship between affect and depression and stress, less is known about its association to mental health more broadly. Often associated with affect is mood, which can be understood as a set of feelings or emotions of various lengths of time and magnitude (e.g., high intensity joy for the week following acceptance to graduate school versus short term low-level sadness after earning a slightly poorer grade than anticipated on a quiz worth 2\%; Lane and Terry 2000). Surprisingly, a database search revealed no studies examining the non-disordered mood of university students; mood-focused research has typically investigated the prevalence and severity of mood disorders in the student population (Auerbach et al. 2016; Duffy et al. 2019). Recently researchers concluded that mood disorders are becoming increasingly more common among young adults, specifically those in post-secondary education (Auerbach et al. 2018; Pedrelli et al. 2015). The rise in clinically diagnosed mood disorders among the student population, in conjunction with the limited research that exists investigating the factors that influence students' mood, suggests that there might be a gap in literature worth exploring.

The mental health of university students - namely stress, social anxiety, negative affect and mood - is concerning. It is imperative to provide students with accessible options to help alleviate stress (Fried and Irwin 2016). One such approach that has demonstrated success in promoting positive mental health among undergraduate students centers around performing acts of kindness (Lyubomirsky et al. 2004; Paviglianiti 
and Irwin 2017; Pressman et al. 2015; Trew and Alden 2015). Acts of kindness are actions that benefit others or enhance the mood of others, typically at some cost to oneself (Lyubomirsky et al. 2004). ${ }^{1}$ Engaging in kind acts has both psychological and physical benefits, specifically in relation to increased life satisfaction, decreased levels of depression, and improvements in wellbeing (Burr et al. 2011; Dulin et al. 2012; Lyubomirsky et al. 2004; Musick and Wilson 2003; Post 2005; Pressman et al. 2015). Lyubomksky et al. (2004) found that compared to a no-treatment control group, students who performed five acts of kindness per week (over a six-week period) experienced elevated feelings of happiness and improved mental wellness. Similarly, Layous et al. (2012) investigated whether acts of kindness could promote wellbeing and social acceptance in youth aged 9-11, in Vancouver, British Columbia. They found that students who performed three acts of kindness per week (over four weeks) experienced stronger improvements in their wellbeing and social acceptance among peers than those in the control group (Layous et al. 2012). Another study included 146 undergraduate psychology students and the researchers investigated the impact of acts of kindness on avoidance goals in socially anxious individuals (Trew and Alden 2015). The authors concluded that engaging in acts of kindness led to a reduction in social avoidance goals in socially anxious individuals, relative to both comparison conditions (Trew and Alden 2015). Further investigating the impact of kindness, a recent study conducted at Western University in Ontario, Canada examined students' experiences in a random acts of kindness (RAKs) health promotion project (Paviglianiti and Irwin 2017). The Butterfly Effect: A Legacy Through Kindness was a voluntary health promotion class project intended to give students an experiential learning opportunity by creating a kindness movement (Paviglianiti and Irwin 2017). Participating students self-reported an increase in their wellbeing, happiness, and confidence, as well as a reduction in stress (Paviglianiti and Irwin 2017). Similarly, Pressman et al. (2015) examined the impact of a 'pay it forward' kindness intervention on both the people engaging in as well as those receiving the kind acts. Eighty-three undergraduate students at a large Midwestern University performed RAKs for $90 \mathrm{~min}$ on a given day, and recorded individuals' reactions (Pressman et al. 2015). Not only did those who received the kindness benefit, but students who engaged in the RAKs reported greater positive affect and lower negative affect (Pressman et al. 2015). Layous et al. (2014) proposed that positive thoughts and behaviors reinforce happiness, and positive activities such as writing letters of gratitude, practicing optimism, and performing acts of kindness may lead to improved mental health. In summary, performing acts of kindness can impact one's wellbeing; however, performing acts of kindness to reduce stress and anxiety and promote positive affect and mood, specifically among university students, is an understudied area.

Given the mental health crisis at universities and the previously published positive effects of acts of kindness on the wellbeing, happiness, social acceptance, and social avoidance goals of students, there is a need to further explore acts of kindness as a mental health intervention for university students (Layous et al. 2012; Lyubomirsky et al. 2004; Mackenzie et al. 2011; Maykrantz and Houghton 2018; Paviglianiti and

\footnotetext{
${ }^{1}$ This information is referenced from an unpublished study by Lyubomirsky et al. (2004), of which the specific details of the study's population are not clear. The principle author was contacted to gain more information; however, the details were not provided.
} 
Irwin 2017; Trew and Alden 2015). Acts of kindness provide an innovative and inexpensive intervention to improve the mental health of undergraduate students, which is paramount at a time when university budgets are stretched thin. With this in mind, the current study assessed the incremental impact of performing acts of kindness, beyond the benefits seen from providing a resource booklet on stress management (that is available to all students at the host institution), with regard to the affect, social interaction anxiety, and mood of undergraduate students.

\section{Methods}

\subsection{Study Design}

A repeated-measures, mixed methods design was used in this study, which ran for two weeks beginning late February to early March 2019. Data was gathered at preintervention (February 2019) and immediate post-intervention (March 2019). This study received ethics approval from the host institution's Health Sciences Research Ethics Board (HSREB \#112790).

\subsection{Participants}

Full-time undergraduate students at a large Canadian University were invited to participate in this study via two masse mail recruitment notices. Interested participants contacted the research team via email and their eligibility was confirmed. To be eligible for inclusion, participants had to be full-time undergraduate students, English-speaking, and willing to participate in the proposed study. Once their eligibility was confirmed, participants electronically signed and returned the consent form. One hundred and forty-two students expressed interest in participating in the study and of these students, 69 were eligible and consented to participating. Due to timing logistics (i.e., completing the study before end-of-term), recruitment ended prior to reaching the goal of 150 participants. Of the 69 participants, 15 were lost at follow-up $(9=$ intervention group; $6=$ comparator group).

\subsection{Procedure}

Participants were asked to complete a pre-intervention questionnaire prior to study start date (February 2019), which was sent to them via an email link, administered through Qualtrics ${ }^{\circledR}$, an online survey tool. Then, participants were randomly assigned to either the comparator $(n=34)$ or intervention group $(n=$ 35) using an Internet-based randomizer (GraphPad Software 2018). Both groups received access, via a clickable link and email-attached PDF, to a relaxation and stress management booklet from the post-secondary institution's Wellness Education Centre. The booklet provided participants with techniques to help them cope effectively in stressful situations. Techniques varied from relaxation practices (e.g., body scan) to stress management (e.g., mindful meditation). The intervention group was also asked to partake in and $\log$ a minimum of three acts of kindness per day for the duration of the 2-week study. While previous 
research indicates that participating in more acts of kindness over a shorter duration is more effective than performing less acts over a longer period of time (i.e., five acts of kindness in one day versus five acts of kindness spread throughout the week; Lyubomirsky et al. 2005), a recent study found that the more acts of kindness one engages in, the happier they will be (Rowland and Curry 2019). Though the ideal dosage of positive activities (e.g., acts of kindness) can be challenging and can vary between individuals (Lyubomirsky and Layous 2013), given that the number of acts of kindness one participates in appears to be directly correlated to their levels of happiness, we decided to ask participants to engage in a minimum of three acts of kindness per day, assuming that it may have a similar effect on the outcomes of social interaction anxiety, affect, and mood. Participants received two email reminders during the 2-week intervention (day 5 and day 10) to remind them of their access to the stress management booklet (comparator group and intervention group) and to complete the acts and the log the activities (intervention group only). Participants were provided with a link to the acts of kindness log, administered through Qualtrics®, where they were asked to submit their acts of kindness daily.

\subsection{Measures}

Pre-test and post-test assessments were the same, with the addition of one open-ended question in the post-test assessment which asked participants about their overall experience being involved in the study. The assessments included a demographic questionnaire, the Brief Mood Introspection Scale (BMIS; Mayer and Gaschke 1988), the Social Interaction Anxiety Scale-Straightforward (SIAS-S; Rodebaugh et al. 2007), and the International Positive and Negative Affect Schedule-Short Form (I-PANAS-SF; Thompson 2007). The intervention group was asked to submit a daily acts of kindness log, which included four questions. See below for assessment descriptions.

\subsubsection{Demographic Questionnaire}

The demographic questionnaire included information about: (a) sex; (b) age; (c) ethnicity; (d) academic enrollment status; (e) place of residence/living arrangement; (f) faculty and year of study; (g) therapy or counselling received; and (h) medication taken for stress, anxiety or mood. All questions were multiple choice with the option to clarify if participants selected 'other'.

\subsubsection{Brief Mood Introspection Scale (BMIS)}

The BMIS was previously validated and assesses mood using 16-items selected from eight mood states (Mayer and Gaschke 1988). Participants indicate how well each adjective or phrase described their present mood ranging from 1 (definitely do not feel) to 4 (definitely feel). Examples of adjectives include: 'Happy', 'Tired', 'Caring', and 'Nervous'. The BMIS includes four sub-scales: (1) Pleasant-Unpleasant; (2) ArousalCalm; (3) Positive-Tired; and (4) Negative-Relaxed. All scoring was done consistent 
with that of Mayer and Gaschke (1988). Specifically, the score for the PleasantUnpleasant subscale was obtained by summing all 16 items, of which eight were reverse-scored. The Arousal-Calm subscale score was obtained by summing 12 items, of which two were reverse-scored. The Positive-Tired subscale score was obtained by summing seven items, of which two were reverse-scored. The score for the NegativeRelaxed subscale was obtained by summing six items, of which one was reversescored.

\subsubsection{Social Interaction Anxiety Scale-Straightforward (SIAS-S)}

The previously validated SIAS-S assesses cognitive, affective, and behavioral aspects of social interaction anxiety on a 20 -item scale with response options ranging from 0 (not at all) to 4 (extremely; Rodebaugh et al. 2007). Scores are summed and a score of 28 or higher (out of 80 ) indicates probable social interaction anxiety.

\subsubsection{International Positive and Negative Affect Schedule-Short Form (I-PANAS-SF)}

The I-PANAS-SF was previously validated, and measures affect using 20 items from the Positive and Negative Affect Schedule $(10$ items = positive affect and 10 items $=$ negative affect; Thompson 2007). Participants indicate the extent they had felt the adjective over the past week on a five-point scale ranging from 1 (very slightly or not at all) to 5 (extremely). Examples of adjectives include: 'Disinterested', 'Enthusiastic', 'Ashamed', and 'Determined'. Scores are then summed for both positive and negative affect, respectively. Higher scores indicate higher levels of affect (positive or negative) and lower scores indicate lower levels of affect (positive or negative).

\subsubsection{Acts of Kindness Log}

In addition to asking participants to track the type, date, and number of acts of kindness in which they engaged, they were also asked to describe their experience participating in these acts.

\subsection{Data Analysis}

\subsubsection{Quantitative Analysis}

All quantitative data was analyzed within the Statistical Package for the Social Sciences (SPSS; version 25). Each of the three primary outcome measures were analyzed separately, using $2 \times 2$ repeated measures ANOVAs, with Type I error rate controlled within each of these families of comparison. In cases where an outcome measure had multiple subscales (i.e., the BMIS and the I-PANAS-SF), multiple comparison bias was controlled by comparing results to alphas that were adjusted according to guidelines associated with a Holm-Bonferroni correction (Holm 1979).

Measures of central tendency and dispersion were computed for the acts of kindness $\log$. The average number of $\log$ submissions per day was calculated and compared to the expected mean of log submissions per day. The average number of acts of kindness per day was computed and compared to the expected mean. 


\subsubsection{Qualitative Analysis}

Responses to the open-ended questions were analysed qualitatively. As advised by Hsieh and Shannon (2005), summative content analysis was used to determine the frequency of different acts of kindness in which participants engaged. Inductive content analysis was employed on the responses to the questions about intervention participants' experiences partaking in acts of kindness as well as all participants' reflections of their overall experience participating in this study (Patton 2015). Inductive content analysis was carried out, independently and simultaneously, by the lead researcher (K.S.) and two undergraduate student research assistants (T.L. \& V.V.) who were trained for this task. As advised by Braun and Clark (2019), first the researchers became immersed in the data by reading through the transcripts several times. Once immersion was obtained, the researchers began line-by-line coding and making notes regarding emerging themes and subthemes. Subthemes were understood as subdeviations to the main theme, which shared the same overarching concept as the main theme but focused on one specific element (Braun and Clark 2019). Next, themes and subthemes were given working titles and definitions and participant quotes were placed into their respective themes and subthemes. Once analyses were finalized individually, the researchers met and compared findings by cross-referencing each theme and subtheme and agreement was reached on the final themes and subthemes. There were no substantive deviations in the researchers' findings.

\section{Results}

\subsection{Participants}

This study included 69 undergraduate students with the majority identifying as female $(n=58 ; 84.1 \%)$ and Caucasian $(n=42 ; 60.9 \%)$, with an average age of $21(\mathrm{SD}=3.28)$. There were no statistically significant differences between the comparator and intervention group, in terms of age $[\mathrm{t}(56)=0.40, p=0.69]$, sex $\left[\chi^{2}(1)=0.076\right]$, use of medications $\left[\chi^{2}(1)=0.54\right]$, or participation in counselling $\left[\chi^{2}(1)=0\right]$. Demographic variables are summarized in Table 1.

\subsection{Quantitative Findings}

None of the analyses were statistically significant, even without controlling for multiple comparison bias. All effects are summarized in Table 2. Furthermore, no substantive change in the interpretation of the quantitative variables was found when the sample was restricted to include only those individuals who were not taking medications for stress, anxiety, or mood, as well as individuals who were not currently in active psychotherapy or counselling.

\subsubsection{Acts of Kindness Engagement}

There was a total of 290 acts of kindness log submissions by the intervention group participants over the course of the two-weeks, with more submissions during week 1 
Table 1 Demographic Information $(N=69)$

\begin{tabular}{|c|c|c|}
\hline Participant Characteristic & $\mathrm{N}$ & $\%$ \\
\hline \multicolumn{3}{|l|}{ Sex } \\
\hline Male & 11 & 15.9 \\
\hline Female & 58 & 84.1 \\
\hline \multicolumn{3}{|l|}{ Ethnicity } \\
\hline African Heritage & 3 & 4.3 \\
\hline East Asian & 7 & 10.1 \\
\hline Caucasian & 42 & 60.9 \\
\hline Hispanic & 2 & 2.9 \\
\hline Middle Eastern & 7 & 10.1 \\
\hline South Asian & 3 & 4.3 \\
\hline Other & 5 & 7.2 \\
\hline \multicolumn{3}{|l|}{ Marital Status } \\
\hline Single & 66 & 95.7 \\
\hline Married/common law/engaged & 3 & 4.3 \\
\hline \multicolumn{3}{|l|}{ Living Arrangement } \\
\hline On campus & 16 & 23.2 \\
\hline Off campus by myself & 2 & 2.9 \\
\hline Off campus with roommates & 31 & 44.9 \\
\hline Off campus with family/relatives & 13 & 18.8 \\
\hline Off campus with spouse/partner & 6 & 8.7 \\
\hline \multicolumn{3}{|l|}{ Faculty } \\
\hline Arts and Humanities & 3 & 4.3 \\
\hline Engineering & 2 & 2.9 \\
\hline Health and Rehabilitation Sciences & 21 & 30.4 \\
\hline Information and Media Studies & 1 & 1.4 \\
\hline Music & 2 & 2.9 \\
\hline Science & 12 & 17.4 \\
\hline Social Science & 6 & 8.7 \\
\hline Huron University College & 2 & 2.9 \\
\hline Brescia University College & 6 & 8.7 \\
\hline Kings University College & 13 & 18.8 \\
\hline Other & 1 & 1.4 \\
\hline \multicolumn{3}{|l|}{ Year of Study } \\
\hline First year & 20 & 29.0 \\
\hline Second year & 12 & 17.4 \\
\hline Third year & 15 & 21.7 \\
\hline Fourth year & 15 & 21.7 \\
\hline Other & 6 & 8.7 \\
\hline \multicolumn{3}{|l|}{ On medication for stress/anxiety/mood } \\
\hline Yes & 19 & 27.5 \\
\hline No & 50 & 72.5 \\
\hline \multicolumn{3}{|l|}{ Receiving therapy/counselling } \\
\hline Yes & 18 & 26.1 \\
\hline No & 50 & 72.5 \\
\hline
\end{tabular}


Table 2 ANOVA results for the Brief Mood Introspection Scale (BMIS), the Social Interaction Anxiety Scale-Straightforward (SIAS-S), and the International-Positive and Negative Affect Schedule-Short Form (I-PANAS-SF)

Scale

Pre-Intervention Post-Intervention F-ratio (Time x Group)

Mean (SD) Mean (SD)

\begin{tabular}{|c|c|c|c|c|}
\hline \multirow[t]{2}{*}{ Pleasant- Unpleasant } & Comparator $(n=28)$ & $41.5(7.04)$ & $41.3(5.63)$ & $F(1,52)=.468, p=.994^{\mathrm{a}}$ \\
\hline & Intervention $(n=26)$ & $41.7(8.25)$ & $42.8(8.04)$ & $\eta_{\text {partial }}^{2}=.009$ \\
\hline \multirow[t]{2}{*}{ Arousal-Calm } & Comparator $(\mathrm{n}=28)$ & $31.0(3.06)$ & $30.1(3.32)$ & $F(1,52)=2.06, p=.632^{1}$ \\
\hline & Intervention $(\mathrm{n}=26)$ & $29.9(4.76)$ & $30.3(4.78)$ & $\eta_{\text {partial }}^{2}=.038$ \\
\hline \multirow[t]{2}{*}{ Positive-Tired } & Comparator $(\mathrm{n}=28)$ & $17.9(3.72)$ & $17.3(2.40)$ & $F(1,52)=1.19, p=.840^{1}$ \\
\hline & Intervention $(n=26)$ & $17.5(4.34)$ & $17.9(4.16)$ & $\eta_{\text {partial }}^{2}=.022$ \\
\hline \multirow[t]{2}{*}{ Negative-Relaxed } & Comparator $(\mathrm{n}=28)$ & $15.2(3.14)$ & $14.8(3.22)$ & $F(1,52)=.073, p=.994^{1}$ \\
\hline & Intervention $(\mathrm{n}=26)$ & $14.7(3.84)$ & $14.5(4.01)$ & $\eta_{\text {partial }}^{2}=.001$ \\
\hline \multicolumn{5}{|c|}{ Social Interaction Anxiety Scale-Straightforward (SIAS-S) } \\
\hline \multirow[t]{2}{*}{ SIAS-S } & Comparator $(\mathrm{n}=28)$ & $29.3(14.1)$ & $24.7(11.4)$ & $F(1,54)=.532, p=.469$ \\
\hline & Intervention $(\mathrm{n}=26)$ & $27.3(16.3)$ & $24.4(12.9)$ & $\eta_{\text {partial }}^{2}=.010$ \\
\hline \multicolumn{5}{|c|}{ International-Positive and Negative Affect Schedule-Short Form (I-PANAS-SF) } \\
\hline \multirow[t]{2}{*}{ Positive Affect } & Comparator $(n=28)$ & $17.86(3.72)$ & $17.25(2.40)$ & $F(1,52)=.002, p>.999^{1}$ \\
\hline & Intervention $(n=26)$ & $17.50(4.34)$ & $17.88(4.16)$ & $\eta_{\text {partial }}^{2}<.001$ \\
\hline \multirow[t]{2}{*}{ Negative Affect } & Comparator $(\mathrm{n}=28)$ & $15.21(3.04)$ & $14.79(3.22)$ & $F(1,52)=.372, p>.999^{1}$ \\
\hline & Intervention $(n=26)$ & $14.65(3.84)$ & $14.46(4.01)$ & $\eta^{2}$ partial $=.007$ \\
\hline
\end{tabular}

$p$ value adjusted using Holm-Bonferroni correction

versus 2 (23 submissions/day versus 18 submissions/day, respectively). The response rate for the $\log$ submissions was $59 \%$ or $290 / 490$. The standard deviation for the number of acts of kindness log submissions was 0.492 . In each submission participants were asked to indicate the number of acts of kindness they completed that day. The number of acts of kindness that were completed also declined from week 1 to week 2 (63 acts/day versus 51 acts/day, respectively). The response rate for the number of acts of kindness submissions was $55 \%$ or $806 / 1470$. The standard deviation for the number of acts of kindness submitted was 0.884 .

\subsection{Qualitative Findings}

\subsubsection{Comparator Group}

Two common themes emerged among the comparator group's responses: (1) skill development; and (2) increased self-reflection/awareness.

Comparator group participants noted the benefit of the relaxation and stress management booklet in developing skills to combat stress and anxiety. Participants described situations where they felt stressed or anxious and were able to better manage such feelings. One participant highlighted their appreciation for the stress management booklet saying, "[The] tips and tricks were helpful. This past week was particularly 
stressful from a personal perspective, but the strategies helped me to get through the situation." The feeling of being able to better manage stressful experiences was paralleled by another participant who stated, "I liked a lot of the techniques presented in the study [the booklet] and it definitely helped me get through panic attacks." Some participants not only expressed that they liked the use of the guide, but that they also planned to incorporate the techniques they learned into their everyday lives. This was expressed by one participant who stated, "I enjoyed it [the booklet], I believe it taught me many worthwhile techniques that will be useful throughout my life." Another participant underscored this further saying, "I liked the use of the guide and will use it in my regular life outside of this study."

Some participants noted an increase in self-reflection by taking part in mindful practices to relieve stress, as suggested in the booklet. Specifically, one participant described how participating in the study prompted introspection that inspired them to begin journaling saying, "The study made me think about my emotions and why I was feeling them more than I have in the past." Another participant echoed the practice of mindfulness to manage stress by saying, "I enjoyed having reminders to do the little things that can improve your health. I also enjoyed how mindful it allowed me to be, while providing stress relieving solutions." Reflecting on their daily habits was both informative and surprising for participants. Specifically, one participant highlighted a technique in the booklet that aided in managing their stress stating, "I felt like it [the booklet] was actually a bit helpful as there were situations where even just taking the time to breathe truly helped me put things in perspective, which helped me work better."

\subsubsection{Intervention Group}

Acts of kindness ranged from everyday activities to others that were more unique. Every day activities included: holding the door open for people $(n=128)$; smiling at $(n=49)$ and greeting strangers $(n=27)$; and offering compliments to people $(n=27)$. Acts of kindness that were more unique in nature included: donating clothes $(n=1)$; shovelling snow from neighbours' driveways $(n=1)$; leaving post-it notes with words of encouragement in areas for people to find $(n=1)$; and handing out chocolate and positive notes to people around campus $(n=1)$.

Participant responses to their experience engaging in the acts of kindness yielded six themes and four subthemes: (1) increased awareness; (2) improved wellbeing (decreased stress and improved mental health, and improved mood); (3) increased selfesteem; (4) fostered connection; (5) reciprocity (response from acts of kindness recipients improved wellbeing of the giver); and (6) engagement in acts of kindness felt effortless (natural, habitual).

Many participants highlighted an increase in their awareness, both internally (i.e., about themselves) and externally (i.e., about others/surroundings). One participant noted, "I really like this study. I normally do a lot of random acts of kindness, but this experiment allowed me to reflect on them to see how it made both myself and others feel." This participant not only highlighted the impact that engaging in the acts of kindness had on others, but also recognized that participating in the acts allowed for emotional self-reflection. Regarding external reflection, one participant noted an increase in their awareness of their surroundings, "including people's alertness... and 
how easy it is to spread happiness." Another participant paralleled this comment by noticing a difference in their awareness of the people around them. Some participants reported making a conscious effort to slow down and reflect upon the impact of their positive acts of kindness, which in turn encouraged them to be kind. This was reflected by one participant who stated:

"I think being involved in this study is making me a bit more mindful of when/how I do kind things for others. Before I would do these things if it was convenient, but I am learning that being kind isn't always convenient and requires (usually temporal) sacrifice. And honestly, I'm totally okay with that. Sometimes I need to slow down, and the conscious choice to be kind almost forces me to do that."

A few participants underscored the role that recording their acts of kindness had on their awareness. Specifically, one participant highlighted that in logging their acts of kindness they were more aware of activities that would otherwise be subconscious saying, "Having to record my RAKs made me a lot more aware of RAKs I would never think about before (i.e., holding the door, smiling at people, etc.)."

The majority of participants noted an improvement in their sense of wellbeing which took various forms including decreased stress and improved mental health, and improved mood. Almost all participants expressed that they 'felt good' after participating in the acts of kindness. This was underscored by one participant who stated, "I felt good being able to anonymously make someone's day. I felt good getting rid of clothes I no longer wear and donating them for people who need clothes and will get better use out of them." Another participant echoed this saying, "It felt good to force myself to think about others to do nice things." Some participants expanded on this saying that participating in the acts of kindness relieved feelings of stress and improved their mental health, as highlighted by one participant who said, "Performing these RAKs are very good for my mental health. I feel very positive doing these RAKs and continue to do them with the intention of purely helping others." A few participants also noted that it felt good to consider the wellbeing of others. This was conveyed by one participant who said, "I think it felt good to do all these helpful things and lessen the load of someone else's, it gave some more meaning to life in my opinion." This participant recognized the causal sequence that considering other people's wellbeing had, namely on their overarching life satisfaction.

Some participants noted that engaging in the acts of kindness relieved feelings of stress as participating in the acts of kindness offered a sense of relief. One participant viewed stress from a different perspective saying, "These RAKs helped me realize that taking a little time out of your day can really help relieve the stresses of everyday life on someone else. It made me feel more helpful and less of a waste of space." Interestingly, this participant discussed stress in relation to other people, rather than themselves. More broadly, a few participants highlighted the positive influence that participating in acts of kindness had on their overall mental health and wellbeing. This was reflected by one participant who stated, "Performing these RAKs are very good for my mental health. I feel very positive doing these RAKs and continue to do them with the intention of purely helping others." Another participant paralleled this comment by stating that engaging in the acts of kindness, specifically with their family and/or partner, contributed to positive mental wellbeing.

The majority of participants noted an improvement in their mood after completing the acts of kindness. Participants described feelings of happiness, joy, and alertness, to 
name a few. Many participants mentioned feelings of happiness post-engagement in the acts of kindness which, in turn, they felt improved their wellbeing. This was reflected by one participant who stated, "Dedicating my time to things that will make other people's lives easier is an important contributor to my personal happiness." Other participants highlighted enjoyment in participating in the acts of kindness. Specifically, one participant noted, "I am feeling much more positive these couple of days and [I am] enjoying going to campus and starting my day in a happier way." This was reiterated by another participant who emphasized an improvement in their outlook as they, "gained a sense of altruism with [their] random acts of kindness." More broadly, many participants found that their overall mood was enhanced which, in turn, helped them to view the world from a more positive lens, rather than focusing on the stress within their lives. This was conveyed by one participant who stated, "I've always thought that doing nice things for others helps better [one's] mood, as it helps focus on the positives, whether that be positive things you can do for others or positive things that happen to you." Furthermore, some participants noted the benefit of utilizing techniques from the stress and relaxation booklet to sustain participation in the acts of kindness which, consequently, improved their mood. One participant exemplified this saying:

"My favourite activities (that I found I could do anywhere), were meditation and deep breathing exercises. During my study breaks I would do these for 5-10 minutes and would feel a dramatic improvement in my overall mood, motivation and focus levels. By doing these multiple times a day, I was able to sustain enough positive energy to complete my daily RAKs without feeling overwhelmed."

The relationship between the stress management booklet and acts of kindness is one that was not mentioned by many participants but warrants consideration.

Many participants reported feeling like a 'better person' knowing they were helping others, which was attributed to an increase in self-esteem. This was underscored by one participant who said, "It makes me feel like a good person to be nice to people without expecting anything in return." Others noted that they felt better about themselves when the acts of kindness had more meaning to them. One participant explained this by providing a personal example:

"When I gave someone advice and they reacted positively to it by saying that I helped them and [that I] made them feel better, I felt good about what I did and I [felt] encouraged to do more actions like that."

This example suggests that engaging in acts of kindness may have both improved the participant's self-esteem, and consequently encouraged the behavior further.

Participating in acts of kindness reportedly cultivated a sense of connection. Some noted a shift in how they communicated with people. Specifically, one participant stated, "Being intentional about RAKs has changed my approach to communicating because I am focused on improving the wellness [of] others." Others underscored the importance in providing kindness to people who might feel alone, as discussed by a participant who said, "It feels good to reach out to people who are alone because I know how much more comfortable I would have felt if someone did the same for me." Many participants described how engaging in the acts of kindness helped to build new relationships or encourage existing ones. This was displayed in various settings including the workplace and the school environment. Specifically, one participant discussed fostered connection in the workplace saying, "I enjoyed my time with my co-worker because it felt like she loved my presence and feelings of care were 
reciprocated." Another participant discussed fostered connection at school stating, "I really enjoyed talking to the girl in my English class because I now feel like I made a new friend and that connection is really important to me." Both of these examples contextualize the importance of relationships, something that was further emphasized by participants as they explained that engaging in the acts of kindness was a gratifying experience and "a good way to spread joy and build relationships."

A number of participants noted an improvement in their wellbeing after witnessing the acts of kindness recipient's response. Many discussed 'feeling good' when the recipient expressed gratitude and appreciation. This was highlighted by one participant who stated, "I felt good doing the RAKs, and even better when I received a positive response afterwards." Another participant paralleled this statement while also emphasizing continual engagement saying, "When I gave someone advice and they reacted positively to it by saying that I helped them and made them feel better, I felt good about what I did, and I feel encouraged to do more actions like that." Some participants mentioned that seeing the acts of kindness receivers' responses enhanced their mood. This was reflected by one participant who noted, "I had a great day as many people provided me with words of gratitude which positively impacted my mood all day as I felt that my efforts to make people's day [were] noticed." Other participants highlighted that seeing the receivers' reactions provided the giver with feelings of joy.

A number of participants expressed that engaging in acts of kindness felt natural for them and/or became a habit throughout study involvement. Many shared that participating in acts of kindness was not outside their normal behavior and required little effort. This was reflected by one participant saying, "Honestly, smiling at people and saying hello is something I do many times a day, so it's natural to me... None of my RAKs seem like an effort." Another participant even mentioned that they felt guilty recording the acts of kindness, as they felt these should be things that people do on a regular basis. This was further emphasized by a participant who stated, "I feel like these are common things that you should do anyways to be a decent human being." Some participants also highlighted that engaging in the acts of kindness became a habit for them. This was reflected by one participant who stated, "At this point in the study, these little convenient RAKs are just becoming a part of my daily routine. I think I have to start doing more substantial things." Participants found that they were engaging in acts of kindness on a regular basis, not just as requirement of the study.

Though the majority of the participants in the intervention group had a positive experience participating in the study, a number also expressed frustration and provided suggestions for improving the logistics of the intervention. Specific challenges included: difficulty understanding what to write in their daily logs, forgetting to submit the logs, difficulty tracking log submissions, and stress from trying to remember to keep track of their acts of kindness. In terms of suggestions for improvement, participants proposed providing participants with examples of completed acts of kindness logs for reference, more reminders throughout the day to complete the logs, and the ability to submit the acts of kindness immediately following the engagement. One participant provided insight on their experience logging their acts of kindness, as well as areas for improvement saying:

"I did find it difficult keeping on top with submitting my daily RAKs. It would be great if there was a way to help us track our daily RAKs (the ability to update our daily 
submissions so I can submit immediate after my RAK) or have a calendar to check off if I've submitting my daily RAK each day. I'm generally a forgetful person!"

Another participant requested that the acts of kindness log provide examples of completed logs for reference stating, "The email prompts really helped and the information the study provided was useful. Although I wish that the log provided specific examples on what to provide for the experience of performing RAKs."

\section{Discussion}

This study assessed the impact of engaging in acts of kindness on the affect, social interaction anxiety, and mood of undergraduate students, compared to a stress management booklet comparator group. The study revealed no statistically significant differences between groups. Rather, participants in both groups reported that their involvement in the study provided an overall positive experience. Those in the comparator group described increased awareness/self-reflection and developed their stress management skills as a result of their engagement with the relaxation and stress management booklet. While the response rates for the acts of kindness log submission and the number of acts of kindness completed each day were lower than expected, the intervention group revealed self-reported improvements in wellbeing, increased awareness and self-esteem, as well as feelings of social connection and reciprocity as a result of engaging in the acts of kindness, and ease participating.

The findings noted above are consistent with previous literature. In the present study we conceptualized wellbeing as a group of constructs that included decreased stress, improved mood, and more broadly, improved mental health. Participants from the intervention group in the current study expressed improvements in each construct noted above. Engaging in the acts of kindness seemingly allowed participants to feel more accomplished, motivated, and optimistic about life, which might have diminished feelings of stress and/or anxiety by enhancing their overall wellbeing. Previously, researchers, using similar although not identical descriptions/components of wellbeing, have also reported that engaging in acts of kindness improved the wellbeing of the actor (Curry et al. 2018; Lyubomirsky et al. 2004; Paviglianiti and Irwin 2017). Intervention participants in the present study also described feelings of increased happiness, which consequently improved their overall mood, as a result of participating in the acts of kindness. This finding is consistent with results from Rowland and Curry (2019) as well as Paviglianiti and Irwin (2017), who found that performing acts of kindness increased feelings of happiness. The improvement in such constructs described by participants potentially positions acts of kindness as a cost-effective solution to the mental health challenges that students experience.

Though it is evident that engaging in acts of kindness promotes improved wellbeing (i.e., improved mood, decreased stress, and improved mental health), less is known about how the receiver's response impacts the wellbeing of the giver (Lyubomirsky et al. 2004; Paviglianiti and Irwin 2017; Rowland and Curry 2019). In the present study, many intervention group participants noted that seeing the reaction of the acts of kindness recipient improved their wellbeing (i.e., increased their happiness and improved their overall mood, made them 'feel good', and encouraged them to continue engaging in the behavior). As a result, many participants preferred performing acts of 
kindness for friends and family because they were able to see the immediate impact, in comparison to performing the acts for strangers. Though there are no kindness studies to date that have investigated this relationship, the impact of the receiver's response on the wellbeing of the giver might be explained in part by the phenomenon positive empathy (Morelli et al. 2015). Positive empathy occurs when individuals observe other people's positive outcomes and subsequently share their affective states (Morelli et al. 2015). The association between positive empathy and acts of kindness can be illustrated via two different studies that found participants to be more likely to help other people when they were told that they would see the positive reaction of the recipient, when compared to those who were told they would not see the reaction (Batson et al. 1991; Smith et al. 1989). Individuals can experience positive empathy from a variety of different people (i.e., strangers, coworkers, acquaintances); however, individuals experience the effects of positive empathy greatest in close relationships (i.e., family, friends, romantic partners; Gable et al. 2004; Gable and Reis 2010).

The enhanced sense of wellbeing reported by the intervention group is consistent with previous literature that aimed to explain this relationship. For instance, Layous et al. (2014) proposed that positive activities, including acts of kindness, have the ability to protect against negative mental health conditions; the skills used to engage in positive activities can mitigate risk factors for mental illness. Kindness, for example, is a tool that people can use when they are forced to deal with negative thoughts and/or behaviors, challenging life events, and stress (Layous et al. 2014). Layous et al. (2014) suggested that performing acts of kindness mitigates the risk factors associated with mental health conditions by improving one's wellbeing, as well as promoting positive views of the self and strengthening relationships. Findings from the current study expanded upon the work of Layous et al. (2014), as participants in the intervention group described improved wellbeing, including decreased stress and, in turn, improved mental health. Acts of kindness might also be viewed as beneficence - the ability to give to others - which has been thought to improve wellbeing (Martela and Ryan 2016). This can be explained, in part, by the basic psychological needs of autonomy, competence, and relatedness (i.e., components of the Self-Determination Theory; Weinstein and Ryan 2010). Martela and Ryan (2016) found that such constructs can explain the wellbeing benefits of beneficence and underscore the role of beneficence as a crucial component of human wellness. Future acts of kindness studies might investigate this relationship further by measuring the satisfaction of these needs. Further, participants highlighted that engaging in the acts of kindness fostered connection with the receivers. This finding suggests that engaging in acts of kindness might encourage new relationships or strengthen existing ones (Layous et al. 2014).

Intervention group participants described an increase in self-esteem via engaging in the acts of kindness. Many noted that they felt like a good person and/or better about themselves having engaged in acts of kindness. This may be due, in part, to the fact that performing acts of kindness typically makes the recipient feel good, which, in turn, has a positive effect on the giver. Participants experienced an increase in self-esteem knowing that they engaged in a behavior that is seemingly culturally valued. This finding is consistent with Layous et al. (2014), who noted that engaging in positive activities might promote positive self-views. It stands to reason that increased self-esteem and the establishment and/or strengthening of relationships all contribute to improved wellbeing which, in turn, can decrease stress and improve one's mental health. 
In Pressman et al.' (2015) study, researchers noted a statistically significant change in participants' mood from pre- to post-intervention. In their study, participants were asked to complete the questionnaires within $24 \mathrm{~h}$ of engaging in the RAKs, as they noted that the effects of the RAK activity diminished over time (Pressman et al. 2015). This differed from the current study, as the researchers did not measure the immediate effect of participating in the acts of kindness. Rather, the questionnaires were administered post-intervention, which may explain why there was no statistically significant change in mood, despite participants in the intervention group qualitatively describing meaningful improvements.

While both control and intervention group participants described increased awareness, the extent and magnitude of the described awareness differed between groups. Control group participants described internal self-reflection/awareness; whereas, the intervention group also reported an external awareness of others/surroundings. Additionally, the intervention group described feelings of social connection, something that was not reported by those in the control group. Broader themes such as these suggest that adding kindness as an intervention is beneficial and provides even more grounds for future research to assess this using larger sample sizes to improve power to detect significant differences between groups on such variables.

\subsection{Limitations and Future Directions}

Participants did not complete the acts of kindness log to the desired extent, and this made it difficult to adequately quantify the extent to which individuals engaged with the intervention. In part, the lack of statistical significance is due to lack of power. This study was conducted as a course requirement for the lead researcher and needed to be completed by end of term. Consequently, recruitment ended prior to reaching the desired sample size. Although 142 students expressed an interest in participating, only 69 confirmed eligibility and consented which may, in part, be due to the cumbersome two-step recruitment protocol (one email confirming eligibility and a second email requesting electronic consent). Going forward, a preliminary power analysis conducted using the pwr package (Champely 2018) in R 3.6.0 (R Core Team 2019) suggested that, all things being equal, future studies should aim to have a sample size of approximately 158 participants per treatment group, assuming an alpha of $0.05,80 \%$ power, and a small-to-medium effect size (approximately $\mathrm{f}^{2}=0.08$ ). Not all intervention group participants completed the acts of kindness log daily and based on their feedback, this was due to it being too taxing timewise. This finding is consistent with Lyubomirsky and Layous (2013), who noted the difficulty in determining the ideal dosage of positive activities, such as acts of kindness, suggesting that "person-activity fit likely governs optimal dosage" (p. 59). Though many participants expressed challenges, they also recommended areas for improvement, including providing examples of competed acts of kindness logs, more reminders throughout the day to complete the $\log$, and the ability to submit the acts of kindness immediately following the engagement. Such recommendations should be taken into consideration for future studies. Although it could be viewed as a limitation, assessing the additive value of acts of kindness to the stress management booklet (versus comparing acts of kindness only to the booklet only) was a valuable first step in identifying that both interventions appear valuable. Moving forward, comparing the two interventions directly may be 
beneficial for identifying which is the more effective approach to improve university students' mental health. As such, we recommend a larger future study that is longerduration and sufficiently powered to assess the interaction between: (1) acts of kindness only; (2) booklet only; and (3) acts of kindness + booklet together.

\section{Conclusions}

There is a strong potential for acts of kindness as a tool to help enhance students' mental health, which may be particularly valuable at a time when universities are experiencing fiscal constraints while trying to support students during increasing levels of mental health challenges. Namely, the intervention group described improvement in their wellbeing, mood, and mental health and decreased levels of stress, which highlights the beneficial nature of acts of kindness as a mental health promotion tool. Although findings were not statistically significant, qualitative responses from participants suggested meaningful impacts that paralleled findings from previous works, with respect to kindness as an intervention for student social interaction anxiety, affect, and mood (Layous et al. 2014; Lyubomirsky et al. 2004; Paviglianiti and Irwin 2017; Pressman et al. 2015; Rowland and Curry 2019). Given its low cost and ease of application, acts of kindness as a health promotion tool holds promise as a unique strategy that can easily and widely be employed on university campuses to support the mental health of undergraduate students during what is ubiquitously described as a stressful time.

Acknowledgements We would like to thank Taylor Labadie's and Varsha Vasudevan's support in helping with the project.

\section{Compliance with Ethical Standards}

Conflict of Interest The authors declare that they have no conflict of interest.

Ethical Approval All procedures performed in studies involving human participants were in accordance with the ethical standards of the institutional and/or national research committee (HSREB \#112790) and with the 1964 Helsinki declaration and its later amendments or comparable ethical standards.

Informed Consent Informed consent was obtained from all individual participants included in the study.

\section{References}

Adlaf, E. M., Gliksman, L., Demers, A., \& Newton-Taylor, B. (2001). The prevalence of elevated psychological distress among Canadian undergraduates: Findings from the 1998 Canadian campus survey. Journal of American College Health, 50(2), 67-72. https://doi.org/10.1080/07448480109596009.

American College Health Association. (2013). American college health association-national college health assessment II: Thompson Rivers University executive summary spring 2013. Silver Spring: American College Health Association.

American College Health Association. (2016). American college health association-national college health assessment II: Ontario Canada reference group executive summary spring 2016. Silver Spring: American College Health Association. 
American Psychiatric Association. (2017). What are anxiety disorders? Retrieved from https://www. psychiatry.org/patients-families/anxiety-disorders/what-are-anxiety-disorders

American Psychological Association. (n.d.-a). APA dictionary of psychology: Positive affect. Retrieved March 13, 2020, from https://dictionary.apa.org/positive-affect

American Psychological Association. (n.d.-b). APA dictionary of psychology: Negative affect. Retrieved March 13, 2020, from https://dictionary.apa.org/negative-affect

Auerbach, R. P., Alonso, J., Axinn, W. G., Cuijpers, P., Ebert, D. D., Green, J. G., et al. (2016). Mental disorders among college students in the World Health Organization world mental health surveys. Psychological Medicine, 46(14), 2955-2970. https://doi.org/10.1017/S0033291716001665.

Auerbach, R. P., Mortier, P., Bruffaerts, R., Alonso, J., Benjet, C., Cuijpers, P., et al. (2018). WHO world mental health surveys international college student project: Prevalence and distribution of mental disorders. Journal of Abnormal Psychology, 127(7), 623-638. https://doi.org/10.1037/abn0000362.

Barker, E. T., Howard, A. L., Villemaire-Krajden, R., \& Galambos, N. L. (2018). The rise and fall of depressive symptoms and academic stress in two samples of university students. Journal of Youth and Adolescence, 47(6), 1252-1266. https://doi.org/10.1007/s10964-018-0822-9.

Batson, C. D., Batson, J. G., Slingsby, J. K., Harrell, K. L., Peekna, H. M., \& Todd, R. M. (1991). Empathic joy and the empathy-altruism hypothesis. Journal of Personality and Social Psychology, 61(3), 413-426. https://doi.org/10.1037/0022-3514.61.3.413.

Baumeister, R., \& Vohs, K. (2007). Encyclopedia of social psychology. California: SAGE Publications, Inc..

Beidel, D. C., Turner, S. M., Stanley, M. A., \& Dancu, C. V. (1989). The social phobia and anxiety inventory: Concurrent and external validity. Behavior Therapy, 20(3), 41-427. https://doi.org/10.1016/S0005-7894 (89)80060-7.

Blanco, C., Okuda, M., Wright, C., Hasin, D. S., Grant, B. F., Liu, S. M., \& Olfson, M. (2008). Mental health of college students and their non-college-attending peers: Results from the National Epidemiologic Study on alcohol and related conditions. Archives of General Psychiatry, 65(12), 1429-1437. https://doi. org/10.1001/archpsyc.65.12.1429.

Brannan, D., Biswas-Diener, R., Mohr, C. D., Mortazavi, S., \& Stein, N. (2013). Friends and family: A crosscultural investigation of social support and subjective well-being among college students. The Journal of Positive Psychology, 8(1), 65-75. https://doi.org/10.1080/17439760.2012.743573.

Braun, V., \& Clark, V. (2019). Answers to frequently asked questions about thematic analysis. Retrieved from The University of Auckland website: https://cdn.auckland.ac.nz/assets/psych/about/ourresearch/documents/Answers $\% 20$ to $\% 20$ frequently $\% 20$ asked $\% 20$ questions $\% 20$ about $\% 20$ thematic $\% 20$ analysis\%20April\%202019.pdf

Brook, C. A., \& Willoughby, T. (2015). The social ties that bind: Social anxiety and academic achievement across the university years. Journal of Youth and Adolescence, 44(5), 1139-1152. https://doi.org/10.1007 /s10964-015-0262-8.

Bruffaerts, R., Mortier, P., Kiekens, G., Auerbach, R. P., Cuijpers, P., Demyttenaere, K., Green, J. G., Nock, M. K., \& Kessler, R. C. (2018). Mental health problems in college freshmen: Prevalence and academic functioning. Journal of Affective Disorders, 225, 97-103. https://doi.org/10.1016/j.jad.2017.07.044.

Burr, J. A., Tavares, J., \& Mutchler, J. E. (2011). Volunteering and hypertension risk in later life. Journal of Aging and Health, 23(1), 24-51. https://doi.org/10.1177/0898264310388272.

Carroll, D., Ginty, A. T., Der, G., Hunt, K., Benzeval, M., \& Phillips, A. C. (2012). Increased blood pressure reactions to acute mental stress are associated with 16-year cardiovascular disease mortality: Stress reactivity and cardiovascular disease mortality. Psychophysiology, 49(10), 1444-1448. https://oi. org/10.1111/j.1469-8986.2012.01463.x.

Champely, S. (2018). Pwr: Basic functions for power analysis (version 1.2-2) [R Foundation for Statistical Computing]. Retrieved from https://CRAN.R-project.org/package=pwr

Chida, Y., \& Steptoe, A. (2010). Greater cardiovascular responses to laboratory mental stress are associated with poor subsequent cardiovascular risk status: A meta-analysis of prospective evidence. Hypertension, 55(4), 1026-1032. https://doi.org/10.1161/HYPERTENSIONAHA.109.146621.

Cook, C. (2014). Becoming a resilient person - The science of stress management [Online lecture series]. Retrieved from www.edx.org

Curry, O. S., Rowland, L. A., Van Lissa, C. J., Zlotowitz, S., McAlaney, J., \& Whitehouse, H. (2018). Happy to help? A systematic review and meta-analysis of the effects of performing acts of kindness on the wellbeing of the actor. Journal of Experimental Social Psychology, 76, 320-329. https://doi.org/10.1016/j. jesp.2018.02.014.

Duffy, M. E., Twenge, J. M., \& Joiner, T. E. (2019). Trends in mood and anxiety symptoms and suiciderelated outcomes among U.S. undergraduates, 2007-2018: Evidence from two national surveys. The Journal of Adolescent Health, 65(5), 590-598. https://doi.org/10.1016/j.jadohealth.2019.04.033. 
Dulin, P. L., Gavala, J., Stephens, C., Kostick, M., \& McDonald, J. (2012). Volunteering predicts happiness among older Māori and non-Māori in the New Zealand health, work, and retirement longitudinal study. Aging \& Mental Health, 16(5), 617-624. https://doi.org/10.1080/13607863.2011.641518.

Fried, R. R., \& Irwin, J. D. (2016). Calmly coping: A motivational interviewing via co-active life coaching (MI-VIA-CALC) pilot intervention for university students with perceived levels of high stress. International Journal of Evidence Based Coaching and Mentoring, 14(1), 16-33.

Gable, S. L., \& Reis, H. T. (2010). Good news! Capitalizing on positive events in an interpersonal context. Advances in Experimental Social Psychology, 42, 195-257. Elsevier. doi:https://doi.org/10.1016/S00652601(10)42004-3.

Gable, S. L., Reis, H. T., Impett, E. A., \& Asher, E. R. (2004). What do you do when things go right? The intrapersonal and interpersonal benefits of sharing positive events. Journal of Personality and Social Psychology, 87(2), 228-245. https://doi.org/10.1037/0022-3514.87.2.228.

Ghaedi, G. H., Tavoli, A., Bakhtiari, M., Melyani, M., \& Sahragard, M. (2010). Quality of life in college students with and without social phobia. Social Indicators Research, 97(2), 247-256. https:/doi. org/10.1007/s11205-009-9500-3.

Gibbons, S., Trette-McLean, T., Crandall, A., Bingham, J. L., Garn, C. L., \& Cox, J. C. (2018). Undergraduate students survey their peers on mental health: Perspectives and strategies for improving college counseling center outreach. Journal of American College Health, 67(6), 1-12. https://doi.org/10.1080 /07448481.2018.1499652.

Graeff, F. G. (2007). Anxiety, panic and the hypothalamus-pituitary-adrenal axis. Brazilian Journal of Psychiatry, 29(1), 3-6. https://doi.org/10.1590/S1516-44462007000500002.

GraphPad Software. (2018). QuickCalcs. Retrieved from https://www.graphpad.com/quickcalcs/randomize1. $\mathrm{cfm}$

Green, M., DeCourville, N., \& Sadava, S. (2012). Positive affect, negative affect, stress, and social support as mediators of the forgiveness-health relationship. The Journal of Social Psychology, 152(3), 288-307. https://doi.org/10.1080/00224545.2011.603767.

Griffin, K. W., Friend, R., Eitel, P., \& Lobel, M. (1993). Effects of environmental demands, stress, and mood on health practices. Journal of Behavioral Medicine, 16(6), 643-661. https://doi.org/10.1007 /BF00844724.

Hamama, L., Ronen, T., Shachar, K., \& Rosenbaum, M. (2013). Links between stress, positive and negative affect, and life satisfaction among teachers in special education schools. Journal of Happiness Studies, 14(3), 731-751. https://doi.org/10.1007/s10902-012-9352-4.

Heinemann, L. V., \& Heinemann, T. (2017). Burnout research: Emergence and scientific investigation of a contested diagnosis. SAGE Open, 7(1), 1-12. https://doi.org/10.1177/2158244017697154.

Holm, S. (1979). A simple sequentially rejective multiple test procedure. Scandinavian Journal of Statistics, 6 , $65-70$.

Hsieh, H. F., \& Shannon, S. E. (2005). Three approaches to qualitative content analysis. Qualitative Health Research, 15(9), 1277-1288. https://doi.org/10.1177/1049732305276687.

Huang, J., Nigatu, Y. T., Smail-Crevier, R., Zhang, X., \& Wang, J. (2018). Interventions for common mental health problems among university and college students: A systematic review and meta-analysis of randomized controlled trials. Journal of Psychiatric Research, 107, 1-10. https://doi.org/10.1016/j. jpsychires.2018.09.018.

Jou, Y. H., \& Fukada, H. (2002). Stress, health, and reciprocity and sufficiency of social support: The case of university students in Japan. The Journal of Social Psychology, 142(3), 353-370. https://doi.org/10.1080 /00224540209603904.

Kirsh, B., Friedland, J., Cho, S., Gopalasuntharanathan, N., Orfus, S., Salkovitch, M., Snider, K., \& Webber, C. (2016). Experiences of university students living with mental health problems: Interrelations between the self, the social, and the school. Work, 53(2), 325-335. https://doi.org/10.3233/WOR-152153.

Lane, A. M., \& Terry, P. C. (2000). The nature of mood: Development of a conceptual model with a focus on depression. Journal of Applied Sport Psychology, 12(1), 16-33. https://doi.org/10.1080 /10413200008404211.

Larsen, J. T., McGraw, A. P., \& Cacioppo, J. T. (2001). Can people feel happy and sad at the same time? Journal of Personality and Social Psychology, 81(4), 684-696. https://doi.org/10.1037/00223514.81.4.684.

Layous, K., Nelson, S. K., Oberle, E., Schonert-Reichl, K. A., \& Lyubomirsky, S. (2012). Kindness counts: Prompting prosocial behavior in preadolescents boosts peer acceptance and well-being. PLoS One, 7(12), 51380. https://doi.org/10.1371/journal.pone.0051380.

Layous, K., Chancellor, J., \& Lyubomirsky, S. (2014). Positive activities as protective factors against mental health conditions. Journal of Abnormal Psychology, 123(1), 3-12. https://doi.org/10.1037/a0034709. 
Leahy, C. M., Peterson, R. F., Wilson, I. G., Newbury, J. W., Tonkin, A. L., \& Turnbull, D. (2010). Distress levels and self-reported treatment rates for medicine, law, psychology and mechanical engineering tertiary students: Cross-sectional study. Australian \& New Zealand Journal of Psychiatry, 44(7), 608-615. https://doi.org/10.3109/00048671003649052.

LeViness, P., Bershad, C., \& Gorman, K. (2016). The association for university and college counseling center directors annual survey. Retrieved from https://taucced.memberclicks. net/assets/documents/Governance/2017\%20aucced\%20survey-public-apr26.pdf

Lyubomirsky, S., \& Layous, K. (2013). How do simple positive activities increase well-being? Current Directions in Psychological Science, 22(1), 57-62.

Lyubomirsky, S., Tkach, C., \& Sheldon, K. M. (2004). [Pursuing sustained happiness through random acts of kindness and counting one's blessings: Tests of two six-week interventions]. Unpublished raw data.

Lyubomirsky, S., Sheldon, K. M., \& Schkade, D. (2005). Pursuing happiness: The architecture of sustainable change. Review of General Psychology, 9(2), 111-131. https://doi.org/10.1037/1089-2680.9.2.111.

Mackenzie, S., Wiegel, J. R., Mundt, M., Brown, D., Saewyc, E., Heiligenstein, E., Harahan, B., \& Fleming, M. (2011). Depression and suicide ideation among students accessing campus health care. The American Journal of Orthopsychiatry, 81(1), 101-107. https://doi.org/10.1111/j.1939-0025.2010.01077.x.

Martela, F., \& Ryan, R. M. (2016). The benefits of benevolence: Basic psychological needs, beneficence, and the enhancement of well-being. Journal of Personality, 84(6), 750-764. https://doi.org/10.1111 /jopy.12215.

Mayer, J. D., \& Gaschke, Y. N. (1988). The experience and meta-experience of mood. Journal of Personality and Social Psychology, 55(1), 102-111. https://doi.org/10.1037/0022-3514.55.1.102.

Maykrantz, S. A., \& Houghton, J. D. (2018). Self-leadership and stress among college students: Examining the moderating role of coping skills. Journal of American College Health, 1-8. https://doi.org/10.1080 /07448481.2018.1515759.

Morelli, S. A., Lieberman, M. D., \& Zaki, J. (2015). The emerging study of positive empathy. Social and Personality Psychology Compass, 9(2), 57-68. https://doi.org/10.1111/spc3.12157.

Musick, M. A., \& Wilson, J. (2003). Volunteering and depression: The role of psychological and social resources in different age groups. Social Science \& Medicine, 56(2), 259-269. https://doi.org/10.1016 /S0277-9536(02)00025-4.

Nima, A. A., Rosenberg, P., Archer, T., \& Garcia, D. (2013). Anxiety, affect, self-esteem, and stress: Mediation and moderation effects on depression. PLoS One, 8(9), 1-8. https://doi.org/10.1371/journal. pone. 0073265 .

Parade, S. H., Leerkes, E. M., \& Blankson, A. N. (2010). Attachment to parents, social anxiety, and close relationships of female students over the transition to college. Journal of Youth and Adolescence, 39(2), 127-137. https://doi.org/10.1007/s10964-009-9396-x.

Passer, M. W., Smith, R. E., Atkinson, M. L., Mitchell, J. B., \& Muirs, D. W. (2008). Psychology: Frontiers and applications. Third Canadian edition. Whitby: McGraw-Hill Ryerson.

Patton, M. Q. (2015). Qualitative research \& evaluation methods (4th ed.). London: Sage Publications.

Paviglianiti, N. C., \& Irwin, J. D. (2017). Students' experiences of a voluntary random acts of kindness health promotion project. Youth Engagement in Health Promotion, 1(3), 1-23.

Pedrelli, P., Nyer, M., Yeung, A., Zulauf, C., \& Wilens, T. (2015). College students: Mental health problems and treatment considerations. Academic Psychiatry, 39(5), 503-511. https://doi.org/10.1007/s40596-0140205-9.

Post, S. G. (2005). Altruism, happiness, and health: It's good to be good. International Journal of Behavioral Medicine, 12(2), 66-77.

Pratt, M., Pancer, S. M., Hunsberger, B., \& Alisat, S. (2004). Bridging troubled waters: Helping students make the transition from high school to university. Guidance \& Counselling, 19(4), 184-190.

Pressman, S. D., Kraft, T. L., \& Cross, M. P. (2015). It's good to do good and receive good: The impact of a 'pay it forward' style kindness intervention on giver and receiver well-being. The Journal of Positive Psychology, 10(4), 293-302. https://doi.org/10.1080/17439760.2014.965269.

R Core Team. (2019). R: A language and environment for statistical computing [R Foundation for Statistical Computing]. Retrieved from https://www.R-project.org/

Rafaeli, E., Rogers, G. M., \& Revelle, W. (2007). Affective synchrony: Individual differences in mixed emotions. Personality and Social Psychology Bulletin, 33(7), 915-932. https://doi.org/10.1177 /0146167207301009.

Rector, N. A., Bourdeau, D., Kitchen, K., \& Joseph-Massiah, L. (2008). Anxiety disorders: An information guide. Canada: Centre for Addiction and Mental Health. 
Rodebaugh, T. L., Woods, C. M., \& Heimberg, R. G. (2007). The reverse of social anxiety is not always the opposite: The reverse-scored items of the social interaction anxiety scale do not belong. Behavior Therapy, 38(2), 192-206. https://doi.org/10.1016/j.beth.2006.08.001.

Rowland, L., \& Curry, O. S. (2019). A range of kindness activities boost happiness. The Journal of Social Psychology, 159(3), 340-343. https://doi.org/10.1080/00224545.2018.1469461.

Schry, A. R., \& White, S. W. (2013). Understanding the relationship between social anxiety and alcohol use in college students: A meta-analysis. Addictive Behaviors, 38(11), 2690-2706. https://doi.org/10.1016/j. addbeh.2013.06.014.

Selye, H. (1956). The stress of life. New York: McGraw-Hill.

Smith, K. D., Keating, J. P., \& Stotland, E. (1989). Altruism reconsidered: The effect of denying feedback on a victim's status to empathic witnesses. Journal of Personality and Social Psychology, 57(4), 641-650. https://doi.org/10.1037/0022-3514.57.4.641.

Sreeramareddy, C. T., Shankar, P. R., Binu, V., Mukhopadhyay, C., Ray, B., \& Menezes, R. G. (2007). Psychological morbidity, sources of stress and coping strategies among undergraduate medical students of Nepal. BMC Medical Education, 7(1), 26. https://doi.org/10.1186/1472-6920-7-26.

Stallman, H. M. (2010). Psychological distress in university students: A comparison with general population data. Australian Psychologist, 45(4), 249-257. https://doi.org/10.1080/00050067.2010.482109.

Statistics Canada. (2010). Trends in the age composition of college and university students and graduates. Retrieved from https://www150.statcan.gc.ca/n1/pub/81-004-x/2010005/article/11386-eng.htm

Statistics Canada. (2019). Health characteristics, annual estimates. Retrieved from https://www150.statcan. gc.ca/t1/tbl1/en/cv.action?pid=1310009601\#timeframe

Stoliker, B. E., \& Lafreniere, K. D. (2015). The influence of perceived stress, loneliness, and learning burnout on university students' educational experience. College Student Journal, 46(1), 146-160.

Strahan, E. Y. (2003). The effects of social anxiety and social skills on academic performance. Personality and Individual Differences, 34(2), 347-366. https://doi.org/10.1016/S0191-8869(02)00049-1.

Strahan, E., \& Conger, A. J. (1998). Social anxiety and its effects on performance and perception. Journal of Anxiety Disorders, 12(4), 293-305. https://doi.org/10.1016/S0887-6185(98)00016-4.

Thompson, E. R. (2007). Development and validation of an internationally reliable short form of the positive and negative affect schedule (PANAS). Journal of Cross-Cultural Psychology, 38(2), 227-242. https://doi.org/10.1177/0022022106297301.

Trew, J. L., \& Alden, L. E. (2015). Kindness reduces avoidance goals in socially anxious individuals. Motivation and Emotion, 39(6), 892-907. https://doi.org/10.1007/s11031-015-9499-5.

Watson, D., Clark, L. A., \& Tellegen, A. (1988). Development and validation of brief measures of positive and negative affect: The PANAS scales. Journal of Personality and Social Psychology, 54(6), 10631070. https://doi.org/10.1037/0022-3514.54.6.1063.

Watson, D., Wiese, D., Vaidya, J., \& Tellegen, A. (1999). The two general activation systems of affect: Structural findings, evolutionary considerations, and psychobiological evidence. Journal of Personality and Social Psychology, 76(5), 820-838.

Weinstein, N., \& Ryan, R. M. (2010). When helping helps: Autonomous motivation for prosocial behavior and its influence on well-being for the helper and recipient. Journal of Personality and Social Psychology, 98, 222-244.

Wongtongkam, N. (2019). Influence of coping, self-esteem and social support on undergraduate students' emotional distress. Health Education, 119(3), 187-201. https://doi.org/10.1108/HE-01-2019-0001.

Publisher's Note Springer Nature remains neutral with regard to jurisdictional claims in published maps and institutional affiliations. 